\title{
Synthesis of High-Density Bulk Tin Monoxide and Its Thermoelectric Properties
}

\author{
Shimpei Kuwahara ${ }^{1, * 1}$, Sora-at Tanusilp ${ }^{1}$, Yuji Ohishi ${ }^{1}$, Hiroaki Muta ${ }^{1}$, \\ Shinsuke Yamanaka ${ }^{1}$ and Ken Kurosaki ${ }^{1,2,3, * 2}$ \\ ${ }^{1}$ Graduate School of Engineering, Osaka University, Suita 565-0871, Japan \\ ${ }^{2}$ Research Institute of Nuclear Engineering, University of Fukui, Tsuruga 914-0055, Japan \\ ${ }^{3}$ JST, PRESTO, Kawaguchi 332-0012, Japan
}

SnSe exhibits exceptionally high thermoelectric (TE) figure of merit $z T$ mainly due to its ultralow lattice thermal conductivity $\left(\kappa_{\text {lat }}\right)$ [L.-D. Zhao et al.: Nature $\mathbf{5 0 8}$ (2014) 373.]. It is considered that strong lattice anharmonicity caused by the lone pair electrons of $\mathrm{Sn}^{2+}$ results in the ultralow $\kappa_{\text {lat. }}$. Here, we focus on $\mathrm{SnO}$ because it has the lone pair electrons of $\mathrm{Sn}^{2+}$ like $\mathrm{SnSe}$. Bulk samples of $\mathrm{SnO}$ were synthesized by low-temperature high-pressure spark plasma sintering and their TE properties were examined. The present study revealed that SnO exhibits very low $\kappa_{\text {lat }}\left(1.44 \mathrm{Wm}^{-1} \mathrm{~K}^{-1}\right.$ at $\left.573 \mathrm{~K}\right)$ compared with $\mathrm{SnO}_{2}$ which has no lone pair electrons. The Grüneisen parameter $(\gamma)$ of $\mathrm{SnO}$ was evaluated to be 1.70 and this high $\gamma$ leads to large lattice anharmonicity and thereby low $\kappa_{\text {lat }}$. Even though SnO has low $\kappa_{\text {lat, }}$, the $z T$ values were significantly low compared with SnSe. The maximum $z T$ value of $\mathrm{SnO}$ was 0.00141 at $573 \mathrm{~K}$. Since the main reason of this low $z T$ is its non-optimized carrier concentration, the $z T$ of $\mathrm{SnO}$ can be enhanced through the carrier concentration optimization. [doi:10.2320/matertrans.E-M2018804]

(Received October 24, 2017; Accepted January 22, 2018; Published March 16, 2018)

Keywords: thermoelectric, tin monoxide, thermal conductivity, Grüneisen parameter, seebeck coefficient, electrical conductivity

\section{Introduction}

Thermoelectric (TE) materials can convert heat into electricity and vice versa. The conversion efficiency of TEs is mainly determined by the materials' properties called dimensionless figure of merit, $z T=S^{2} \sigma T / \kappa$, where $S$ is the Seebeck coefficient, $\sigma$ is the electrical conductivity, $T$ is the absolute temperature, and $\kappa$ is the total thermal conductivity ( $\kappa=\kappa_{\text {lat }}+\kappa_{\mathrm{el}}$, sum of the contributions from lattice and electronic). ${ }^{1)}$ Thus, to enhance the $z T$, high electrical properties, i.e. high $S^{2} \sigma$, as well as low $\kappa$ are required. Since there exists a trade-off relationship among $S$ and $\sigma$ or $\kappa_{\mathrm{el}}$ depending on the carrier concentration, the most effective way to enhance $z T$ is the reduction of $\kappa_{\text {lat }}$, which is nearly independent of the carrier concentration.

The reduction of $\kappa_{\text {lat }}$ with keeping high electrical properties has been demonstrated in many TE materials, including filled-skutterudites ${ }^{2-4)}$ and nanostructured materials. ${ }^{5-10)}$ In the filled-skutterudites, $A M_{4} X_{12}$, the $A$ atoms called filler elements are bonded weakly to the other atoms and rattles, leading to strong scattering of phonons, resulting in low $\kappa_{\text {lat. }}{ }^{11)}$ In the nanostructured materials, the nanoscale intermediates scatter phonons much more effectively than carriers, when the size of the structure is smaller than the phonon mean free path but larger than the carrier mean free path, leading to a reduction in $\kappa_{\text {lat }}$ without a negative effect on the electrical properties. ${ }^{12,13)}$ On the other hand, a new concept of lattice anharmonicity to reduce $\kappa_{\text {lat }}$ has been proposed recently. ${ }^{14-20)}$ For example, an extremely low $\kappa_{\text {lat }}$ $\left(0.23 \pm 0.03 \mathrm{Wm}^{-1} \mathrm{~K}^{-1}\right.$ at $\left.973 \mathrm{~K}\right)$ was obtained in $\left.\mathrm{SnSe},{ }^{21}\right)$ and it has been considered that this significantly reduced $\kappa_{\text {lat }}$ is mainly due to the high rate of lattice anharmonicity induced by the lone pair electrons of $\mathrm{Sn}^{2+}$. This anharmonicity is driven by a stereochemically active lone pair electrons produced by the interaction between $\mathrm{Sn}(5 \mathrm{p})$

\footnotetext{
${ }^{* 1}$ Graduate Student, Osaka University

${ }^{* 2}$ Corresponding author, E-mail: kurosaki@see.eng.osaka-u.ac.jp
}

and antibonding Sn $(5 \mathrm{~s})-\mathrm{X}$ (p) states. ${ }^{22)}$ Owing to this quite low $\kappa_{\text {lat }}$, SnSe exhibits record-high $z T$ value of $2.6 \pm 0.3$ at $923 \mathrm{~K}^{21)}$ However, despite having very high $z T$, usability of $\mathrm{SnSe}$ is limited by several disadvantages of using Se, because Se is highly toxic and small production scale. ${ }^{23,24)}$

Here, we focus on $\mathrm{SnO}$ which has lone pair electrons of $\mathrm{Sn}^{2+}$ like $\mathrm{SnSe}$ as $\mathrm{O}$ is in the same group 16 elements as $\mathrm{Se}^{22)}$ A fine bulk sample of $\mathrm{SnO}$ is hard to be synthesized because $\mathrm{SnO}$ is decomposed into $\mathrm{SnO}_{2}$ and $\mathrm{Sn}$ between 700 and $1050 \mathrm{~K}^{25)}$ It is reported that the following disproportionation reactions of $\mathrm{SnO}$ occur in a $\mathrm{N}_{2}$ atmosphere:

$$
\begin{aligned}
4 \mathrm{SnO}(s) & \rightarrow \mathrm{Sn}_{3} \mathrm{O}_{4}(s)+\mathrm{Sn}(l) \\
\mathrm{Sn}_{3} \mathrm{O}_{4}(s) & \rightarrow 2 \mathrm{SnO}_{2}(s)+\mathrm{Sn}(l),
\end{aligned}
$$

This is why the physical properties of bulk $\mathrm{SnO}$ have been hardly measured so far. In this paper, we report on the temperature-dependent $\kappa_{\text {lat }}$ and the Grüneisen parameter $(\gamma)$ at room temperature of $\mathrm{SnO}$ and discuss the relationship among the lone pair electrons, anharmonicity, and $\kappa_{\text {lat }} \gamma$ can be used as a measure of anharmonicity. For further discussion of the influence of the lone pair electrons on the $\kappa_{\text {lat }}$, we compared the $\kappa_{\text {lat }}$ and $\gamma$ values of $\mathrm{SnO}$ with those of $\mathrm{SnO}_{2}$ which has no lone pair electrons. Figures 1(a) and 1(b) show the crystal structures of $\mathrm{SnO}$ and $\mathrm{SnO}_{2}$, respectively. $\mathrm{SnO}$ has a tetragonal structure with the space group $P 4 / \mathrm{nmm},{ }^{26)}$ while $\mathrm{SnO}_{2}$ has a tetragonal structure with the space group $\mathrm{P}_{2} /$ mnm. ${ }^{27)}$ Unlike $\mathrm{SnO}_{2}$ with a three dimensional structure, $\mathrm{SnO}$ has a layered structure where the lone pair electrons of $\mathrm{Sn}^{2+}$

(a)

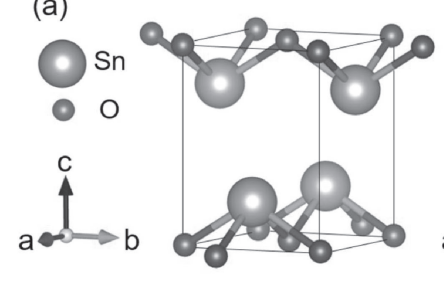

(b)

Fig. 1 Three-dimensional crystal structures of (a) $\mathrm{SnO}$ and (b) $\mathrm{SnO}_{2}$. 
above the apexes of $\mathrm{SnO}_{4}$ square-based pyramids reside in the interstitial space between the layers. ${ }^{28}$ Such a structural feature is expected to be responsible for strong lattice anharmonicity.

\section{Experimental Procedure}

SnO (200 mesh, 99.9\%, Furuuchi Chemical Co. Ltd.) powders were used as raw materials to prepare the bulk samples. To determine the sintering conditions, hightemperature stability of $\mathrm{SnO}$ was checked by the thermogravimetry/differential thermal analysis (TG-DTA) measurement both in air and an Ar atmosphere with a heating rate of $20 \mathrm{Kmin}^{-1}$. The $\mathrm{SnO}$ powders were placed into a tungsten-carbide die, followed by spark-plasma-sintering (SPS) in an Ar flow atmosphere under four different pressure/temperature conditions (\#1 $500 \mathrm{MPa} / 573 \mathrm{~K}$, \#2 $500 \mathrm{MPa} / 598 \mathrm{~K}$, \#3 $500 \mathrm{MPa} / 623 \mathrm{~K}$, and \#4 $300 \mathrm{MPa} /$ $673 \mathrm{~K}$ ). The powders used for the SPS condition \#2 were ball-milled at a rotational speed of $300 \mathrm{rpm}$ for $10 \mathrm{~min}$ before the sintering process. In addition to $\mathrm{SnO}$, commerciallyavailable $\mathrm{SnO}_{2}$ tablets $(\phi 10.0 \mathrm{~mm}$, height $5.0 \mathrm{~mm}, 99.99 \%$, 88.5\%T.D., Kojundo Chemical Laboratory Co., Ltd.) were prepared and their physical properties were characterized to compare the data with those of $\mathrm{SnO}$. The phase state and microstructure of the samples were evaluated at room temperature by powder X-ray diffraction analysis (XRD; Ultima IV, Rigaku Co.) with $\mathrm{Cu} \mathrm{K} \alpha$ radiation and scanning electron microscopy (SEM, JSM-6500F, JEOL) equipped with an energy dispersive spectrometer (EDS). $\kappa$ was calculated by $\kappa=\alpha C_{\mathrm{P}} d$, where $\alpha, C_{\mathrm{P}}$, and $d$ are the thermal diffusivity, specific heat capacity at constant pressure, and density, respectively. $\alpha$ parallel to the SPS (pressing) direction was measured in the temperature range from room temperature to $673 \mathrm{~K}$ in an $\mathrm{Ar}$ atmosphere using a light flash apparatus (Netzsch LFA-467). The $C_{\mathrm{P}}$ data were obtained from the literatures. ${ }^{29,30)} d$ was calculated from the measured weight and dimensions of the bulk samples. $\kappa_{\text {lat }}$ was calculated by subtracting $\kappa_{\mathrm{el}}$ from $\kappa$, where $\kappa_{\mathrm{el}}$ was estimated by the Wiedemann-Franz law, i.e. $\kappa_{\mathrm{el}}=L T \sigma(L$ is the Lorenz number for nondegenerate limit: $\left.1.5 \times 10^{-8} \mathrm{~W} \Omega \mathrm{K}^{-2}\right)$. The volumetric thermal expansion coefficient $\left(\alpha_{\mathrm{V}}\right)$ was evaluated by two methods, high temperature XRD analysis in a He atmosphere and direct measurement using a dilatometer in an Ar flow atmosphere. The $\alpha_{\mathrm{V}}$ perpendicular to the press direction was measured using a dilatometer. The $\alpha_{\mathrm{V}}$ of $\mathrm{SnO}$ and $\mathrm{SnO}_{2}$ were evaluated in the temperature ranges from room temperature to $673 \mathrm{~K}$ and $973 \mathrm{~K}$, respectively. The longitudinal $\left(v_{1}\right)$ and transverse speed of sound $\left(v_{\mathrm{t}}\right)$ were measured by an ultrasonic pulse-echo method at room temperature in air using $10 \mathrm{MHz}$ sound wave echogenic transducers. These properties were measured in the parallel to the press direction. $S$ and $\sigma$ of the bulk samples of $\mathrm{SnO}$ were simultaneously measured in the temperature range from room temperature to $573 \mathrm{~K}$ using a commercial apparatus (Advance Riko ZEM-3) under a $\mathrm{He}$ atmosphere. These properties were measured in the perpendicular to the press direction. The Hall coefficient $\left(R_{\mathrm{H}}\right)$ was measured by the Van der Pauw technique with a Hall measurement system (Toyo Resitest8300) at room temperature in vacuum under an applied magnetic field of
$0.5 \mathrm{~T}$. The Hall carrier concentration $\left(n_{\mathrm{H}}\right)$ and Hall mobility $\left(\mu_{\mathrm{H}}\right)$ were calculated from the expressions $n_{\mathrm{H}}=1 /\left|R_{\mathrm{H}}\right| e$ (e: elementary electric charge) and $\mu_{\mathrm{H}}=\left|R_{\mathrm{H}}\right| \sigma$, respectively.

\section{Results and Discussion}

It was confirmed from the XRD analysis that the asreceived $\mathrm{SnO}$ powders and $\mathrm{SnO}_{2}$ tablet are single phase materials with no remarkable impurities (Fig. 2). Figures 3(a) and 3(b) show the TG-DTA curves of as-received $\mathrm{SnO}$ powders performed in an Ar-flow atmosphere and in air, respectively. As can be seen in Fig. 3(a), $\mathrm{SnO}$ exhibits good thermal stability in an Ar-flow atmosphere up to around $1000 \mathrm{~K}$. On the other hand, $\mathrm{SnO}$ oxidizes in air at around $700 \mathrm{~K}$. In case of the complete oxidation of $\mathrm{SnO}$ to $\mathrm{SnO}_{2}$, the mass change is around $12 \%$. However, in the present case, the mass change is only $1.6 \%$, which can be confirmed from the TG curve in Fig. 3(b). This result means that the oxidation occurs only at the surface of the $\mathrm{SnO}$ powders and thus $\mathrm{SnO}_{2}$ layers act as barriers for farther oxidation. From the TG-DTA results, we determined the SPS conditions.

The powder XRD patterns of the bulk samples of $\mathrm{SnO}$ synthesized by SPS are shown in Fig. 4, together with the literature data of $\mathrm{SnO},{ }^{31)} \mathrm{SnO}_{2},{ }^{32)}$ and $\mathrm{Sn}^{33)}$ It can be confirmed that the samples \#1 $(573 \mathrm{~K}, 500 \mathrm{MPa})$ and \#2 $(598 \mathrm{~K}, 500 \mathrm{MPa})$ are almost pure $\mathrm{SnO}$, while the samples \#3 $(623 \mathrm{~K}, 500 \mathrm{MPa})$ and \#4 $(673 \mathrm{~K}, 300 \mathrm{MPa})$ contain $\mathrm{SnO}_{2}$ clearly as an impurity phase. At $623 \mathrm{~K}$ and above, the sample is stable during the TG-DTA measurement while it

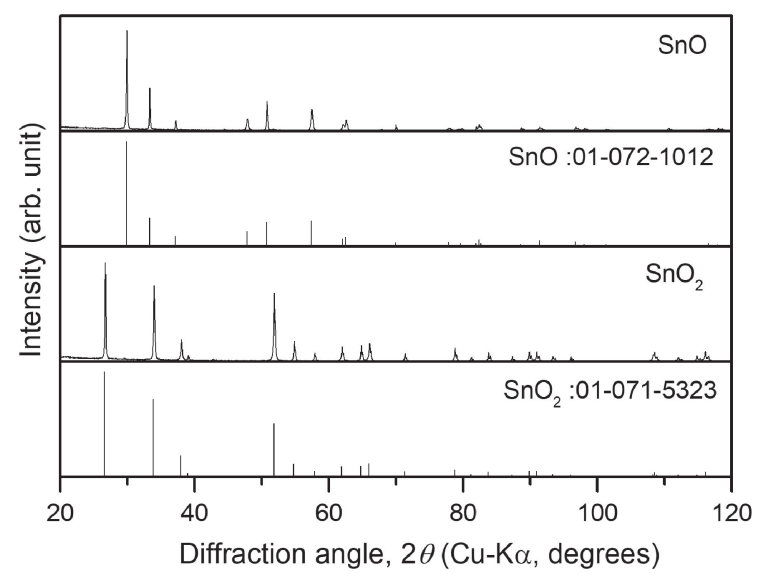

Fig. 2 Powder XRD patterns of as-received $\mathrm{SnO}$ powders and $\mathrm{SnO}_{2}$ tablet, together with the literature data of $\mathrm{SnO}^{31)}$ and $\mathrm{SnO}_{2}{ }^{32}$ )
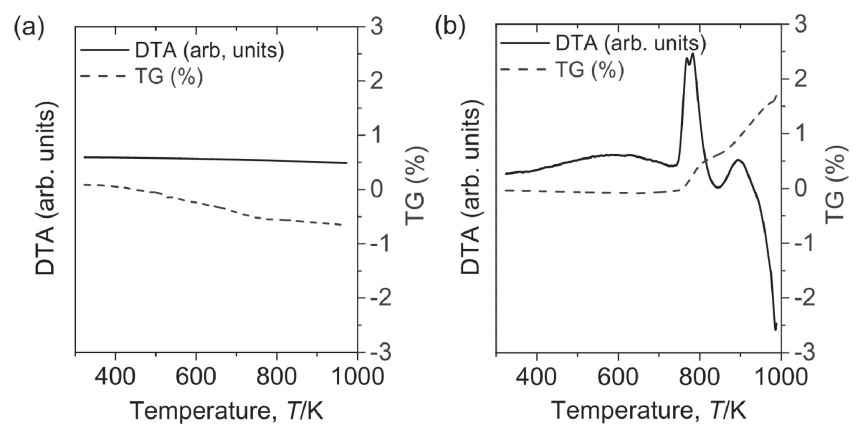

Fig. 3 TG-DTA curves of as-received SnO powders, (a) in an Ar-flow atmosphere and (b) in air. 


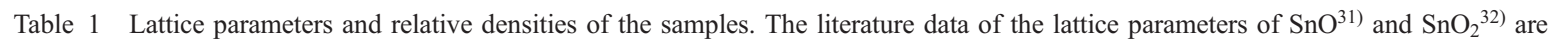
shown for comparison.

\begin{tabular}{|c|c|c|c|c|}
\hline & & \multicolumn{2}{|c|}{ Lattice parameter $(\mathrm{nm})$} & \multirow{2}{*}{$\begin{array}{c}\text { Relative density } \\
\text { (\%T.D.) }\end{array}$} \\
\hline & & a & $\mathrm{c}$ & \\
\hline \multirow{6}{*}{$\mathrm{SnO}$} & As-received powders & $0.3797(16)$ & $0.4830(19)$ & - \\
\hline & SPS bulk \# 1 & $0.3788(12)$ & $0.4832(17)$ & 85.2 \\
\hline & SPS bulk \# 2 & $0.3795(10)$ & $0.4824(14)$ & 90.2 \\
\hline & SPS bulk \# 3 & $0.3795(15)$ & $0.473(5)$ & 89.6 \\
\hline & SPS bulk \# 4 & $0.3792(7)$ & $0.4828(15)$ & 87.6 \\
\hline & Reference data ${ }^{31}$ & 0.38029 & 0.48382 & - \\
\hline \multirow{2}{*}{$\mathrm{SnO}_{2}$} & As-received tablet & $0.4726(3)$ & $0.3183(2)$ & 88.5 \\
\hline & Reference data ${ }^{32}$ & 0.47367 & 0.31855 & - \\
\hline
\end{tabular}

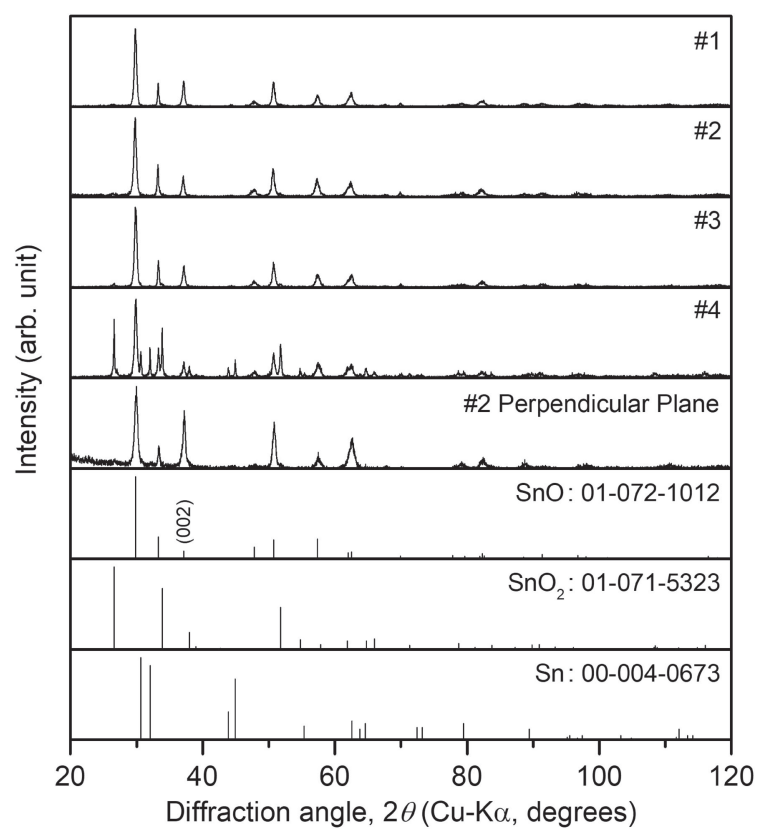

Fig. 4 Powder XRD patterns of the bulk samples of SnO synthesized by SPS and bulk XRD pattern of sample \#2 for the perpendicular plane to the SPS (pressing) direction, together with the literature data of $\mathrm{SnO},{ }^{31}$ ) $\mathrm{SnO}_{2},{ }^{32)}$ and $\mathrm{Sn}^{33)}$

decomposes during the SPS process. It has been reported that the decomposition rate of $\mathrm{SnO}$ into $\mathrm{SnO}_{2}$ and $\mathrm{Sn}$ remarkably increases under high pressure $(2-15 \mathrm{GPa}) .{ }^{34)}$ Therefore, the decomposition rate would also increase under the SPS pressure $(500 \mathrm{MPa})$, which leads to the decomposition of the sample during the SPS process. Table 1 summarizes the lattice parameters and densities of the samples. Among the $\mathrm{SnO}$ samples, the lattice parameters are slightly different each other, likely due to the slight differences in the $\mathrm{O} / \mathrm{Sn}$ ratio. The sample \#2 exhibits the highest relative density of $90.2 \%$, thus, we used this sample for physical properties measurements. The bulk XRD pattern of sample \#2 for the perpendicular plane to the SPS (pressing) direction is shown in Fig. 4. It is confirmed that the intensity of the (002) peak of the bulk sample is slightly higher than that of the powder sample, meaning that the bulk sample is slightly oriented to the [001] direction. Although the bulk sample is slightly (a)

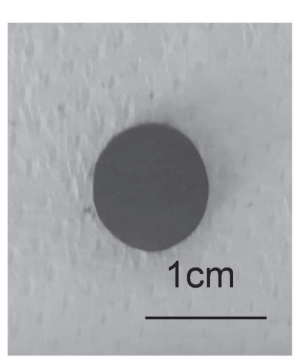

(b)

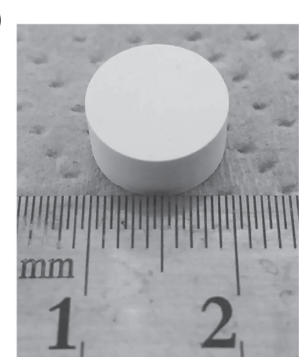

Fig. 5 Appearance of the bulk samples of (a) $\mathrm{SnO}$ (sample \#2) and (b) asreceived $\mathrm{SnO}_{2}$ tablet.
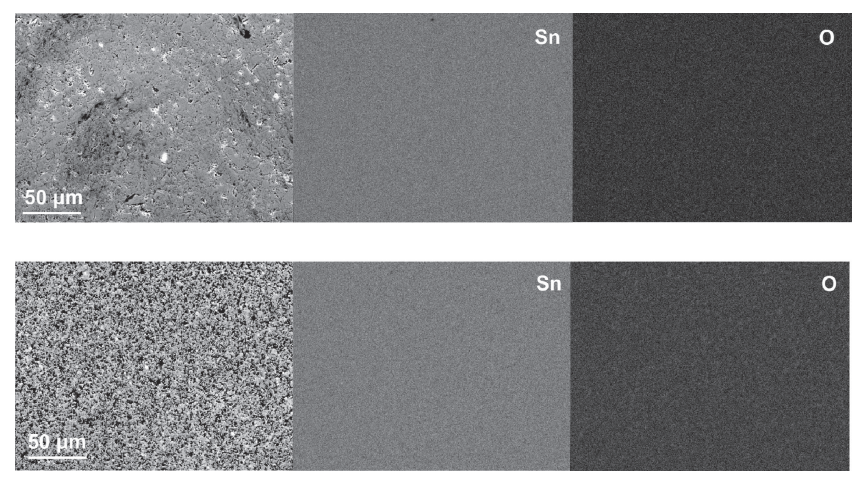

Fig. 6 SEM and EDX mapping images of (top three images) the bulk sample of $\mathrm{SnO}$ (sample \#2) and (bottom three images) as-received $\mathrm{SnO}_{2}$ tablet.

oriented to the [001] direction, the physical properties are evaluated under the assumption that the sample is not anisotropic but isotropic. The appearance of the bulk sample of $\mathrm{SnO}$ (sample \#2) and as-received $\mathrm{SnO}_{2}$ tablet is shown in Figs. 5(a) and 5(b), respectively. Due to the difference in the band gap energy $\left(E_{\mathrm{g}}\right), \mathrm{SnO}\left(E_{\mathrm{g}}=0.73 \mathrm{eV}^{35)}\right)$ is black colored, while $\mathrm{SnO}_{2}\left(E_{\mathrm{g}}=3.64 \mathrm{eV}^{36)}\right)$ is white. Figure 6 shows SEM images and the EDX mapping images of the bulk sample of $\mathrm{SnO}$ (sample \#2) and as-received $\mathrm{SnO}_{2}$ tablet. Both samples are homogeneous and no remarkable cracks and pores. $\mathrm{SnO}_{2}$ tablet has slightly smaller grains $(<\sim 5 \mu \mathrm{m})$ than those of the $\mathrm{SnO}$ bulk sample. The white area in the SEM image of $\mathrm{SnO}$ may correspond to $\mathrm{SnO}_{2}$ existed as the impurity phase. 
Figure 7 shows the temperature dependences of the lattice thermal conductivities $\left(\kappa_{\text {lat }}\right)$ of $\mathrm{SnO}$ and $\mathrm{SnO}_{2}$. Since $\sigma$ values of both $\mathrm{SnO}$ and $\mathrm{SnO}_{2}$ are very small, $\kappa_{\mathrm{el}}$ can be neglected, i.e., $\kappa \approx \kappa_{\text {lat }}$. In the present study, the samples contain pores, thus the Maxwell-Eucken equation was adopted for the correction of porosity in $\kappa_{\text {lat }}$. The equation is expressed as follows: ${ }^{37)}$

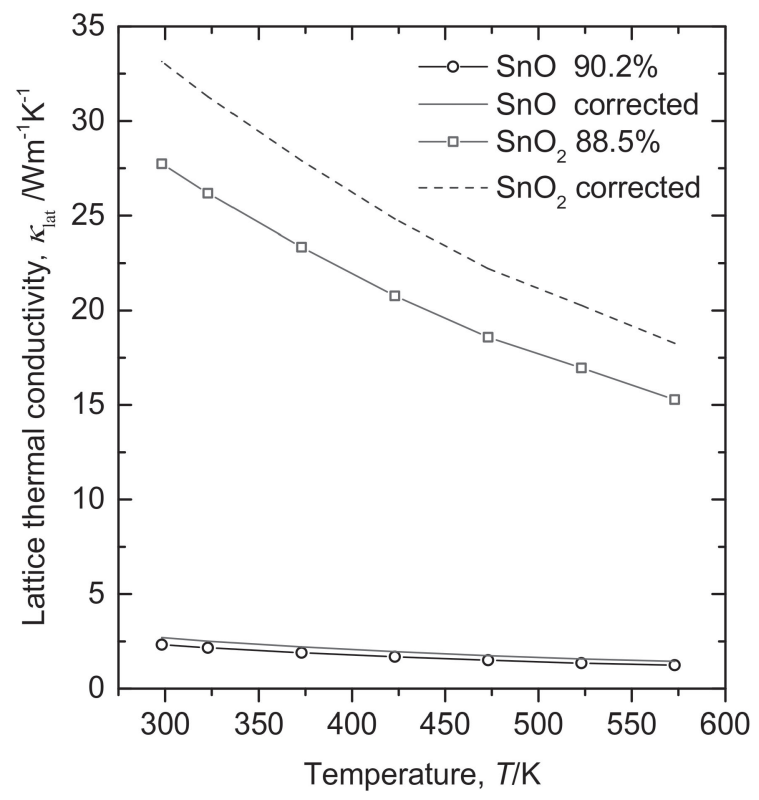

Fig. 7 Temperature dependence of the lattice thermal conductivity $\left(\kappa_{\text {lat }}\right)$ of the bulk sample of $\mathrm{SnO}$ (sample \#2) and as-received $\mathrm{SnO}_{2}$ tablet. Densitycorrected data are shown in lines.

$$
\kappa_{0}=\kappa_{\mathrm{P}} \frac{(1+\beta P)}{(1-P)}
$$

where $\kappa_{0}$ is the thermal conductivity with no pores, $\kappa_{\mathrm{P}}$ is the thermal conductivity of a sample with porosity $P$, and $\beta$ is a constant depending on the shape of the pores (here, $\left.\beta=0.5^{38)}\right)$. The density-corrected $\kappa_{\text {lat }}$ are plotted along with the measured data. As can be confirmed in Fig. 7, $\mathrm{SnO}$ has much smaller $\kappa_{\text {lat }}$ values than $\mathrm{SnO}_{2}$.

To understand the origin of the low $\kappa_{\text {lat }}$ of $\mathrm{SnO}$ compared with $\mathrm{SnO}_{2}$, the $\kappa_{\text {lat }}$ is analyzed by using various physical properties obtained in the present study. Figure 8 shows the temperature dependences of the lattice parameters and lattice volume of $\mathrm{SnO}$ and $\mathrm{SnO}_{2}$ obtained by the HT-XRD measurement. It can be confirmed that all the parameters of both $\mathrm{SnO}$ and $\mathrm{SnO}_{2}$ increase linearly with increasing temperature. The average linear thermal expansion coefficient $\left(\alpha_{\mathrm{L}}\right)$ and the average volumetric thermal expansion coefficient $\left(\alpha_{\mathrm{V}}\right)$ are determined by the following equations:

$$
\begin{aligned}
\alpha_{\mathrm{L}} & =\frac{1}{l_{0}} \frac{d L}{d T}, \\
\alpha_{\mathrm{V}} & =\frac{1}{V_{0}} \frac{d V}{d T},
\end{aligned}
$$

where $l_{0}$ and $V_{0}$ are the lattice parameter and lattice volume at room temperature, respectively. The values of $\alpha_{\mathrm{L}}$ along the $a$-axis $\left(\alpha_{\mathrm{a}}\right)$ and $c$-axis $\left(\alpha_{\mathrm{c}}\right)$ and $\alpha_{\mathrm{V}}$ are summarized in Table 2. The $\alpha_{\mathrm{V}}$ of $\mathrm{SnO}\left(9.97 \times 10^{-5} \mathrm{~K}^{-1}\right)$ is clearly larger than that of $\mathrm{SnO}_{2}\left(1.89 \times 10^{-5} \mathrm{~K}^{-1}\right)$, showing that larger anharmonicity of $\mathrm{SnO}$ than that of $\mathrm{SnO}_{2}$. As for $\mathrm{SnO}$, the $\alpha_{\mathrm{c}}(5.21 \times$ $\left.10^{-5} \mathrm{~K}^{-1}\right)$ is larger than the $\alpha_{\mathrm{a}}\left(2.33 \times 10^{-5} \mathrm{~K}^{-1}\right)$, which is consistent with the fact that $\mathrm{SnO}$ is bounded by a strong (a)

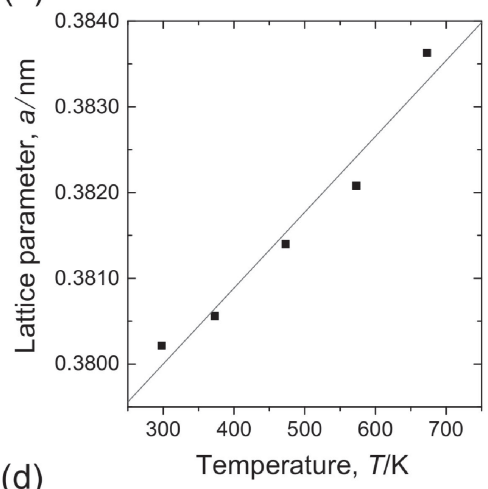

(d)

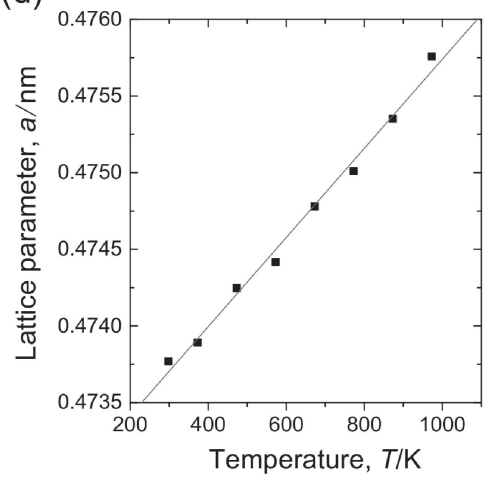

(b)

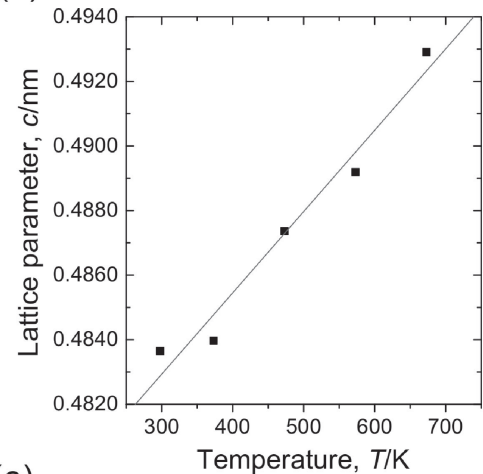

(e)

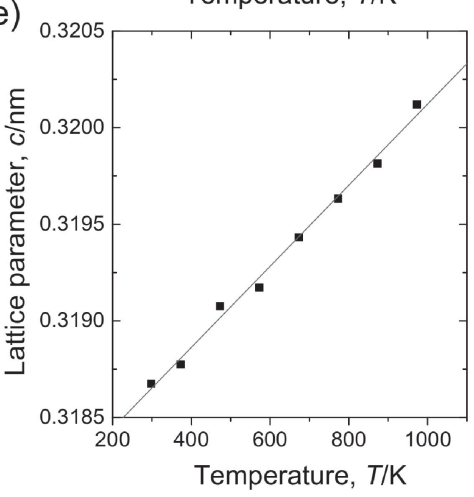

(c)

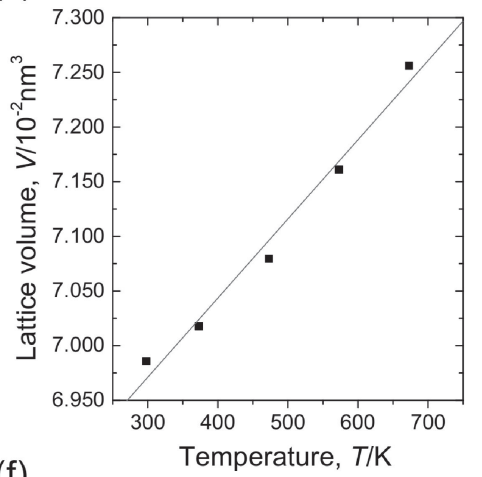

(f)

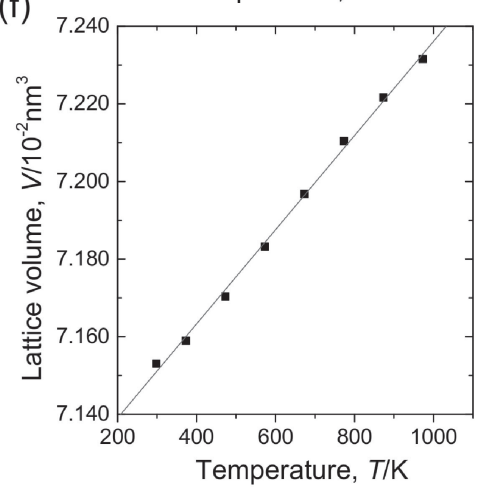

Fig. 8 Temperature dependences of the lattice parameters $a$ and $c$, and lattice volume $V$ of $\mathrm{SnO}$ (top three figures) and $\mathrm{SnO}_{2}$ (bottom three figures). 
Table 2 Linear thermal expansion coefficient along the $a$-axis $\alpha_{\mathrm{a}}$, linear thermal expansion coefficient along the $c$-axis $\alpha_{\mathrm{c}}$, linear thermal expansion coefficient $\alpha_{\mathrm{L}}$, volumetric thermal expansion coefficient $\alpha_{\mathrm{V}}$, longitudinal speed of sound $v_{\mathrm{l}}$, transverse speed of sound $v_{\mathrm{t}}$, average speed of sound $v_{\mathrm{m}}$, Debye temperature $\theta_{\mathrm{D}}$, bulk modulus $B$, and Grüneisen parameter $\gamma$ of $\mathrm{SnO}$ and $\mathrm{SnO}_{2}$. The thermal expansion data are the average values in the temperature range between 300 and $700 \mathrm{~K}$ for $\mathrm{SnO}$ and 300 and $1000 \mathrm{~K}$ for $\mathrm{SnO}_{2}$. The data of the speed of sound are the density-corrected ones. The literature data for $\mathrm{SnO}_{2}{ }^{32,42,43)}$ are shown for comparison.

\begin{tabular}{cccc}
\hline & $\mathrm{SnO}$ & $\mathrm{SnO}_{2}$ & Remarks \\
\hline$\alpha_{\mathrm{a}}\left(\mathrm{K}^{-1}\right)$ & $2.33 \times 10^{-5}$ & $6.14 \times 10^{-6}$ & Evaluated by temperature dependence of \\
$\alpha_{\mathrm{c}}\left(\mathrm{K}^{-1}\right)$ & $5.21 \times 10^{-5}$ & $6.58 \times 10^{-6}$ & the lattice parameters obtained from the \\
$\alpha_{\mathrm{V}}\left(\mathrm{K}^{-1}\right)$ & $9.97 \times 10^{-5}$ & $1.89 \times 10^{-5}$ & high-temperature XRD analysis \\
\hline$\alpha_{\mathrm{L}}\left(\mathrm{K}^{-1}\right)$ & $1.86 \times 10^{-5}$ & $5.87 \times 10^{-6}$ & Measured directly by using a dilatometer \\
$\alpha_{\mathrm{V}}\left(\mathrm{K}^{-1}\right)$ & $5.57 \times 10^{-5}$ & $1.76 \times 10^{-5}$ & - \\
\hline$v_{1}\left(\mathrm{~m} \mathrm{~s}^{-1}\right)$ & 3970 & $7956\left(7141^{42}\right)$ & - \\
$v_{\mathrm{t}}\left(\mathrm{m} \mathrm{s}^{-1}\right)$ & 2670 & $4490\left(4090^{42}\right)$ & - \\
$v_{\mathrm{m}}\left(\mathrm{m} \mathrm{s}^{-1}\right)$ & 2910 & $4990\left(4544^{42}\right)$ & - \\
$\theta_{\mathrm{D}}(\mathrm{K})$ & 335 & $574\left(522^{42}, 570^{43}\right)$ & - \\
$B(\mathrm{GPa})$ & 40.8 & $235\left(185^{42}, 205^{32}\right)$ & \\
\hline$\gamma$ & 1.70 & 1.27 & - \\
\hline \hline
\end{tabular}

covalent bond in the $a$-axis direction, while by a weak van der Waals force in the $c$-axis direction. ${ }^{39)}$ As shown in Fig. 1, $\mathrm{SnO}$ has a layered structure in the $c$-axis direction, while $\mathrm{SnO}_{2}$ does not have such structure.

To check the validity of the values of $\alpha_{\mathrm{L}}$ and $\alpha_{\mathrm{V}}$, we evaluated the parameters by direct measurements using a dilatometer (TD5000SA, Bruker AXS Inc.) under an Ar atmosphere. The temperature range was set as $300-673 \mathrm{~K}$ for $\mathrm{SnO}$ and $300-973 \mathrm{~K}$ for $\mathrm{SnO}_{2}$. In the dilatometer measurement, the $\alpha_{\mathrm{L}}$ can be defined by the following equation:

$$
\alpha_{\mathrm{L}}=\frac{1}{L_{0}} \frac{\Delta L}{\Delta T}
$$

where $L_{0}$ is the initial length, $\Delta L$ is the change of the length, and $\Delta T$ is the change of the temperature. The $\alpha_{\mathrm{V}}$ can be calculated using the following relationship:

$$
\alpha_{\mathrm{V}}=3 \alpha_{\mathrm{L}}
$$

Figure 9 shows the results of the dilatometer measurement. It can be confirmed that $\mathrm{SnO}$ shows larger thermal expansion than $\mathrm{SnO}_{2}$. The $\alpha_{\mathrm{L}}$ and $\alpha_{\mathrm{V}}$ determined by the dilatometer measurements are summarized in Table 2. The $\alpha_{\mathrm{V}}$ of $\mathrm{SnO}$ and $\mathrm{SnO}_{2}$ are $5.57 \times 10^{-5} \mathrm{~K}^{-1}$ and $1.76 \times 10^{-5} \mathrm{~K}^{-1}$, respectively. These smaller values than those determined by the HT-XRD measurements would be caused by the effect of porosity. It has been suggested that the porosity suppressed the thermal expansion of bulk samples. ${ }^{40)}$

In order to obtain accurate values of the sound velocity, the porosity correction was performed by using the measured sound velocities for three bulk samples of $\mathrm{SnO}$ with different porosity. The value corresponding to the sample with zero porosity was evaluated by linear extrapolation. ${ }^{41)}$ Since it was difficult to prepare several samples of $\mathrm{SnO}_{2}$ with different porosity, the porosity correction for $\mathrm{SnO}_{2}$ was done by using the same parameter obtained for SnO. The values obtained by the porosity correction of the longitudinal speed of sound $\left(v_{1}\right)$ and transverse speed of sound $\left(v_{t}\right)$ are summarized in

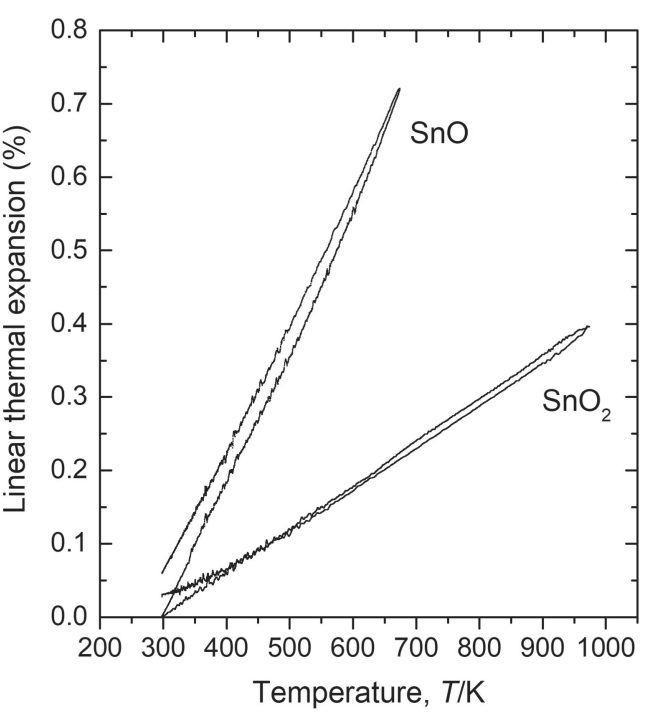

Fig. 9 Linear thermal expansion of $\mathrm{SnO}$ and $\mathrm{SnO}_{2}$, measured by using a dilatometer.

Table 2, together with the literature data of $\mathrm{SnO}_{2} \cdot{ }^{32,42,43)}$ The average speed of sound $\left(v_{\mathrm{m}}\right)$, Debye temperature $\left(\theta_{\mathrm{D}}\right)$, and bulk modulus $(B)$ were calculated using the following equations: ${ }^{44,45)}$

$$
\begin{gathered}
v_{\mathrm{m}}^{-3}=\frac{\left(v_{1}^{-3}+2 v_{\mathrm{t}}^{-3}\right)}{3}, \\
B=d_{0}\left(v_{1}^{2}-\frac{4}{3} v_{\mathrm{t}}^{2}\right), \\
\theta_{\mathrm{D}}=v_{\mathrm{m}}\left(\frac{h}{k_{\mathrm{B}}}\right)\left(\frac{3 n N_{\mathrm{A}} d_{0}}{4 \pi M_{\mathrm{W}}}\right)^{\frac{1}{3}},
\end{gathered}
$$

where $d_{0}$ is the theoretical density, $h$ is the Planck constant, $k_{\mathrm{B}}$ is the Boltzmann constant, $n$ is the number of atoms in the molecule, $N_{\mathrm{A}}$ is the Avogadro constant, and $M_{\mathrm{W}}$ is the molecular weight. The calculated values of the $v_{\mathrm{m}}, B$, and $\theta_{\mathrm{D}}$ of $\mathrm{SnO}$ are summarized in Table 2, together with the 
literature data for $\mathrm{SnO}_{2}$. It was confirmed that $v_{\mathrm{m}}, B$, and $\theta_{\mathrm{D}}$ of $\mathrm{SnO}$ are smaller than those of $\mathrm{SnO}_{2}$.

The Grüneisen parameter $(\gamma)$ which is related to the anharmonicity can be calculated as follows: ${ }^{46)}$

$$
\gamma=\frac{\alpha_{\mathrm{V}} B V_{\mathrm{M}}}{C_{\mathrm{V}}}
$$

where $V_{\mathrm{M}}$ is the molar volume, $C_{\mathrm{V}}$ is the specific heat at constant volume which can be estimated by using DulongPetit law $\left(C_{\mathrm{V}}=3 n R\right.$ where $R$ is the gas constant), and $\alpha_{\mathrm{V}}$ is the volumetric thermal expansion coefficient evaluated by the HT-XRD method. Lattice anharmonicity is closely related with $\alpha_{\mathrm{V}}$, viz., large $\alpha_{\mathrm{V}}$ means large anharmonicity. Therefore, the Grüneisen parameter $(\gamma)$ can provide an indication of degree of anharmonicity as $\gamma$ is proportional to $\alpha_{\mathrm{V}}$ according to eq. (10). As summarized in Table 2, the calculated $\gamma$ values were 1.70 for $\mathrm{SnO}$ and 1.27 for $\mathrm{SnO}_{2}$. $\mathrm{SnO}$ with lone pair electrons clearly exhibits high $\gamma$ value than $\mathrm{SnO}_{2}$ with no lone pair electrons.

In order to find which parameter contributes to the difference in the $\kappa_{\text {lat }}$ of $\mathrm{SnO}$ and $\mathrm{SnO}_{2}$, we analyzed the $\kappa_{\text {lat }}$ based on the following equation: ${ }^{47)}$

$$
\kappa_{\text {lat }}=A \frac{M \delta \theta_{\mathrm{D}}^{3}}{N^{2 / 3} \gamma^{2}} \frac{1}{T},
$$

where $A$ is a constant independent of the material, $M$ is the average molar mass per atom, $\delta^{3}$ is the average volume per atom, $N$ is the number of atoms in the unit cell. At high temperatures above $\theta_{\mathrm{D}}$ where Umklapp phonon-phonon scattering is dominant, the $\kappa_{\text {lat }}$ can be calculated by eq. (11). Furthermore, the Grüneisen parameter $(\gamma)$ is related to the relaxation time for Umklapp phonon-phonon scattering $\left(\tau_{\mathrm{U}}\right)$, i.e., $\tau_{\mathrm{U}}$ is proportional to $\gamma^{-2}$. $\left.{ }^{48}\right)$ Figure 10 shows the ratios of the parameters $\left(\mathrm{SnO} / \mathrm{SnO}_{2}\right)$ of individual contributions for determination of $\kappa_{\text {lat }}$, where the ratio below 1 means that the parameter contributes to the lower $\kappa_{\text {lat }}$ of $\mathrm{SnO}$ than that of $\mathrm{SnO}_{2}$. As can be seen in Fig. 10, the $\mathrm{SnO} /$ $\mathrm{SnO}_{2}$ ratios for $\gamma$ and $\theta_{\mathrm{D}}$ are less than 1 , meaning that these parameters are dominant contributors to lowering $\kappa_{\text {lat }}$ of $\mathrm{SnO}$. Since the ratio for $\theta_{\mathrm{D}}$ is smaller than that for $\gamma$, it can be said that the $\theta_{\mathrm{D}}$ is more predominant than $\gamma$ to reduce the $\kappa_{\text {lat }}$ of $\mathrm{SnO}$.

Figure 11 shows the temperature dependences of (a) $\sigma$, (b) $S$, (c) power factor $S^{2} \sigma$, and (d) $z T$ of the bulk sample of $\mathrm{SnO}$ (sample \#2). As can be seen in Fig. 11, these parameters increase with increasing temperature. The $S$ values are positive, indicating that the $\mathrm{SnO}$ sample is $p$-type. The maximum values of the power factor and $z T$ are $3.76 \mu \mathrm{Wm}^{-1} \mathrm{~K}^{-2} @ 523 \mathrm{~K}$ and $0.00141 @ 573 \mathrm{~K}$, respectively. Very recently, Miller et al. reported the experimental results on the TE properties of polycrystalline SnO bulk samples. ${ }^{49)}$ These data are summarized in Table 3, together with the data of our sample. The $n_{\mathrm{H}}$ of our sample $\left(2.8 \times 10^{18} \mathrm{~cm}^{-3}\right.$ at room temperature $)$ is clearly larger than the reported value $\left(1.0 \times 10^{16} \mathrm{~cm}^{-3}\right.$ at room temperature) . The difference in the $n_{\mathrm{H}}$ between our sample and the sample reported in Ref. 49 would be caused by the difference in the amount of impurities existed in the samples. Miller et al. synthesized the $\mathrm{SnO}$ powders through a precipitation reaction method using $\mathrm{SnCl}_{2}$ as a precursor, where high-

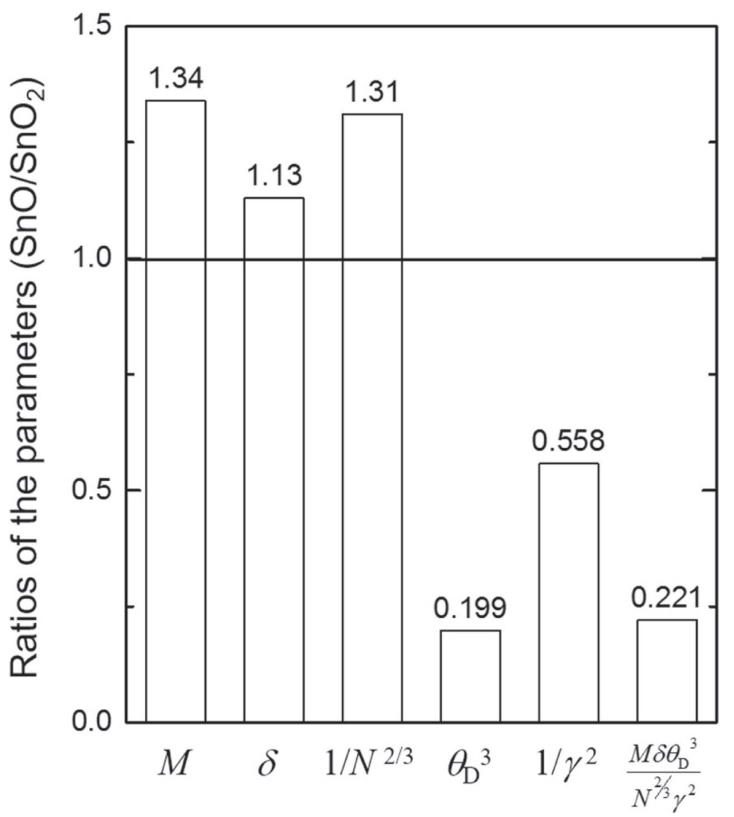

Fig. 10 Ratios of the parameters $\left(\mathrm{SnO} / \mathrm{SnO}_{2}\right)$ of individual contributions for determination of $\kappa_{\text {lat }}$.

Table 3 Results of the Hall effect measurements and the Seebeck coefficient of the bulk sample of SnO (sample \#2). The literature data for $\mathrm{SnO}^{49}$ are shown for comparison. All the data are obtained at room temperature.

\begin{tabular}{cccccc}
\hline \hline & $\begin{array}{c}\text { Carrier } \\
(\Omega \mathrm{cm})\end{array}$ & $\begin{array}{c}\mathrm{n}_{\mathrm{H}} \\
\text { type }\end{array}$ & $\begin{array}{c}\mu_{\mathrm{H}} \\
\left(\mathrm{c} \mathrm{m}^{-3}\right)\end{array}$ & $\begin{array}{c}\mathrm{S} \\
\left(\mathrm{c} \mathrm{m}^{2} \mathrm{~V}^{-1} \mathrm{~s}^{-1}\right)\end{array}$ & $\left(\mu \mathrm{VK}^{-1}\right)$ \\
\hline $\mathrm{SnO}$ & 7.36 & $\mathrm{p}$ & $2.8 \times 10^{18}$ & 0.30 & 371 \\
$\mathrm{SnO}^{49}$ & 40 & $\mathrm{p}$ & $1.0 \times 10^{16}$ & 30 & 635 \\
\hline \hline
\end{tabular}

purity $\mathrm{SnO}$ powders compared with the commercial grade could be obtained. Here, we used commercially-available SnO powders (99.9\%), and impurities existed in the powders would act as hole dopants and increase the $n_{\mathrm{H}}$. Due to this large $n_{\mathrm{H}}$, our sample shows small $S$ and low $\mu_{\mathrm{H}}$ compared with those reported in the literature. We will try to enhance the TE properties of $\mathrm{SnO}$ through the carrier concentration optimization. The results will be reported in near future.

\section{Conclusion}

It is considered that $\mathrm{SnO}$ can be a good TE material because it has lone pair electrons and thereby has large anharmonicity and low $\kappa_{\text {lat }}$. However, a fine bulk sample of $\mathrm{SnO}$ has been never synthesized because $\mathrm{SnO}$ is easily decomposed into $\mathrm{SnO}_{2}$ and $\mathrm{Sn}$ even at $700 \mathrm{~K}$. In the present study, we succeeded in synthetizing high-density pure bulk $\mathrm{SnO}$ samples by using high-pressure and low-temperature SPS (500 MPa, $598 \mathrm{~K})$. It was revealed that $\mathrm{SnO}$ has much smaller $\kappa_{\text {lat }}$ values $\left(1.44 \mathrm{Wm}^{-1} \mathrm{~K}^{-1}\right.$ at $\left.573 \mathrm{~K}\right)$ than $\mathrm{SnO}_{2}$ which has no lone pair electrons. It was confirmed that not only large Grüneisen parameter $(\gamma=1.70)$ but also low Debye temperature $\left(\theta_{\mathrm{D}}=335 \mathrm{~K}\right)$ contributes to this low $\kappa_{\text {lat }}$ of SnO. Furthermore, we reported the TE properties of $\mathrm{SnO}$, where the maximum values of the power factor and 
(a)

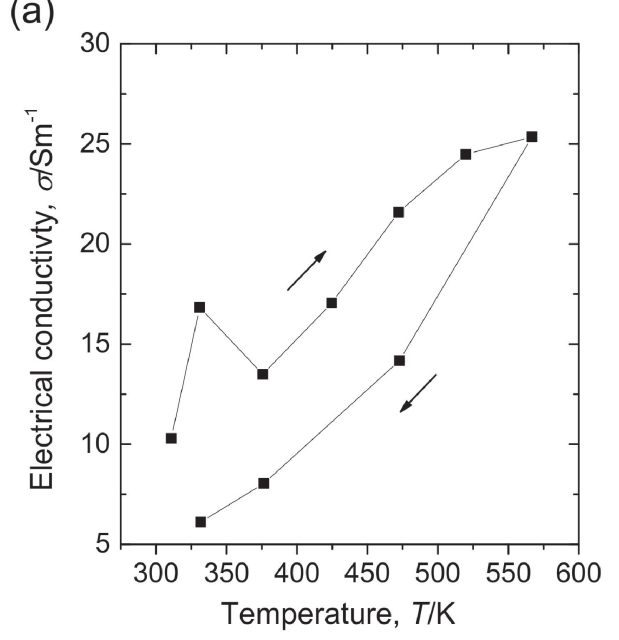

(c)

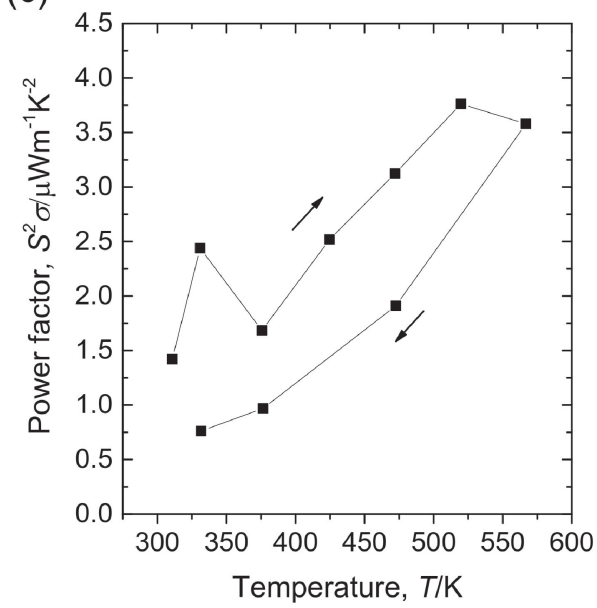

(b)

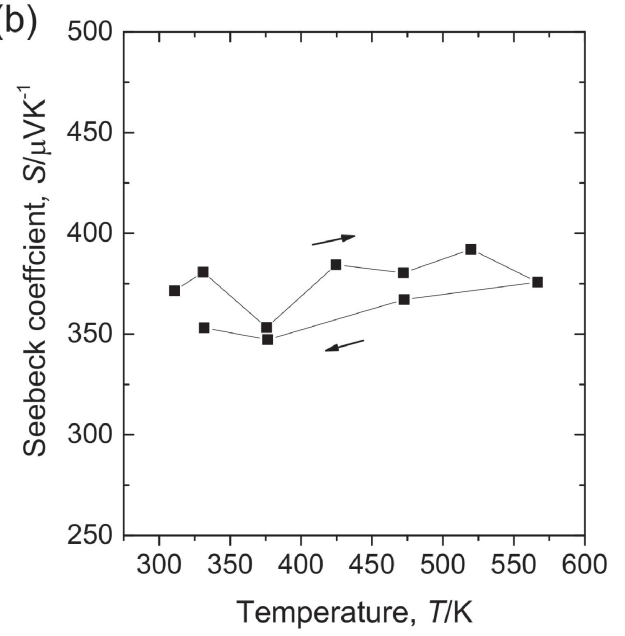

(d)

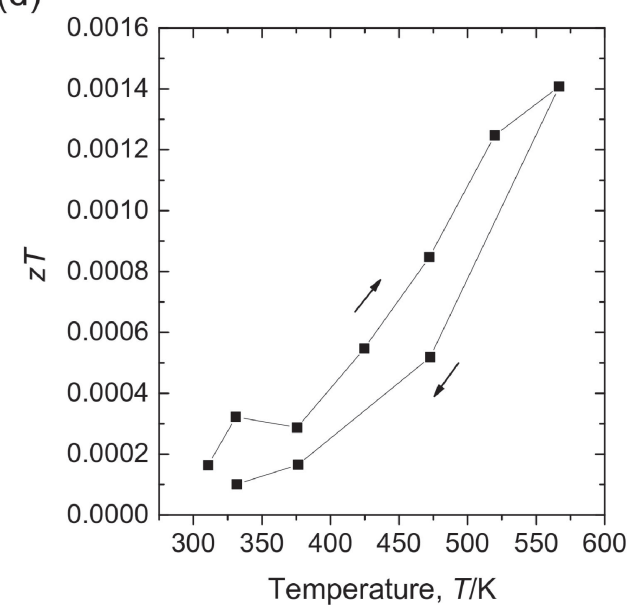

Fig. 11 Temperature dependences of (a) electrical conductivity $\sigma$, (b) Seebeck coefficient $S$, (c) power factor $S^{2} \sigma$, and (d) dimensionless figure of merit $z T$ of the bulk sample of $\mathrm{SnO}$ (sample \#2).

$z T$ are $3.76 \mu \mathrm{Wm}^{-1} \mathrm{~K}^{-2} @ 523 \mathrm{~K}$ and $0.00141 @ 573 \mathrm{~K}$, respectively. The TE properties can be enhanced through the carrier concentration optimization.

\section{Acknowledgments}

This work was supported in part by JST, PRESTO Grant Number JPMJPR15R1.

\section{REFERENCES}

1) G.J. Snyder and E.S. Toberer: Nat. Mater. 7 (2008) 105-114.

2) B.C. Sales, D. Mandrus and R.K. Williams: Science 272 (1996) 13251328.

3) X. Shi, H. Kong, C.-P. Li, C. Uher, J. Yang, J.R. Salvador, H. Wang, L. Chen and W. Zhang: Appl. Phys. Lett. 92 (2008) 182101.

4) X. Shi, J. Yang, J.R. Salvador, M. Chi, J.Y. Cho, H. Wang, S. Bai, J. Yang, W. Zhang and L. Chen: J. Am. Chem. Soc. 133 (2011) $7837-$ 7846.

5) A.I. Hochbaum, R. Chen, R.D. Delgado, W. Liang, E.C. Garnett, M. Najarian, A. Majumdar and P. Yang: Nature 451 (2008) 163-167.

6) A.I. Boukai, Y. Bunimovich, J. Tahir-Kheli, J.-K. Yu, W.A. Goddard, III and J.R. Heath: Nature 451 (2008) 168-171.

7) S.K. Bux, R.G. Blair, P.K. Gogna, H. Lee, G. Chen, M.S. Dresselhaus, R.B. Kaner and J.P. Fleurial: Adv. Funct. Mater. 19 (2009) 2445-2452.

8) P.F.P. Poudeu, J. D’Angelo, A.D. Downey, J.L. Short, T.P. Hogan and
M.G. Kanatzidis: Angew. Chem. Int. Ed. 45 (2006) 3835-3839.

9) T. Mokari, M. Zhang and P. Yang: J. Am. Chem. Soc. 129 (2007) 9864-9865.

10) Y. Pei, N.A. Heinz, A. LaLonde and G.J. Snyder: Energy Environ. Sci. 4 (2011) 3640-3645.

11) M. Christensen, A.B. Abrahamsen, N.B. Christensen, F. Juranyi, N.H. Andersen, K. Lefmann, J. Andreasson, C.R.H. Bahl and B.B. Iversen: Nat. Mater. 7 (2008) 811-815.

12) A.J. Minnich, M.S. Dresselhaus, Z.F. Ren and G. Chen: Energy Environ. Sci. 2 (2009) 466-479.

13) B. Qiu, Z. Tian, A. Vallabhaneni, B. Liao, J.M. Mendoza, O.D. Restrepo, X. Ruan and G. Chen: EPL (Europhysics Lett.) 109 (2015) 57006.

14) C. Xiao, X. Qin, J. Zhang, R. An, J. Xu, K. Li, B. Cao, J. Yang, B. Ye and Y. Xie: J. Am. Chem. Soc. 134 (2012) 18460-18466.

15) S.N. Guin, A. Chatterjee, D.S. Negi, R. Datta and K. Biswas: Energy Environ. Sci. 6 (2013) 2603-2608.

16) S.N. Guin and K. Biswas: Chem. Mater. 25 (2013) 3225-3231.

17) Y.-L. Pei, H. Wu, J. Sui, J. Li, D. Berardan, C. Barreteau, L. Pan, N. Dragoe, W.-S. Liu, J. He and L.-D. Zhao: Energy Environ. Sci. 6 (2013) 1750-1755.

18) D.T. Morelli, V. Jovovic and J.P. Heremans: Phys. Rev. Lett. 101 (2008) 035901.

19) Y. Zhang, E. Skoug, J. Cain, V. Ozolins, D. Morelli and C. Wolverton: Phys. Rev. B 85 (2012) 1-6.

20) M.D. Nielsen, V. Ozolins and J.P. Heremans: Energy Environ. Sci. 6 (2013) 570-578.

21) L.-D. Zhao, S.-H. Lo, Y. Zhang, H. Sun, G. Tan, C. Uher, C. 
Wolverton, V.P. Dravid and M.G. Kanatzidis: Nature 508 (2014) 373377.

22) A. Walsh and G.W. Watson: J. Phys. Chem. B 109 (2005) 1886818875 .

23) W.M. Haynes: CRC Handbook of Chemistry and Physics, 91st Edition (CRC Press, Boca Raton, Fla., 2010) p. 4.

24) T. Nishiyama: RARE METAL RESOURCE (Maruzen Publishing Co. Ltd., Japan, 2009) p. 22.

25) F. Lawson: Nature 215 (1967) 955-956.

26) W.J. Moore, Jr and L. Pauling: J. Am. Chem. Soc. 63 (1941) $1392-$ 1394.

27) W.H. Baur: Acta Crystallogr. 9 (1956) 515-520.

28) R. Seshadri: J. Chem. Sci. 113 (2001) 487-496.

29) I. Barin, O. Knacke and O. Kubaschewski: Thermochemical Properties of Inorganic Substances (Springer-Verlag Berlin Heidelberg, 1977) p. 702 .

30) I. Barin, F. Sauert, E. S.-Rhonhof and W.S. Sheng: Thermochemical Data of Pure Substances (Weinheim, New York, VCH, 1989) p. 1404

31) J. Pannetier and G. Denes: Acta Crystallogr. Sec. B 36 (1980) $2763-$ 2765.

32) J. Haines and J.M. Léger: Phys. Rev. B 55 (1997) 11144-11154.

33) H. Swanson and E. Tatge: Natl. Bur. Stand. Circ. 539 (1953) 24.

34) H. Giefers, F. Porsch and G. Wortmann: Solid State Ion. 176 (2005) $1327-1332$.
35) J.B. Varley, A. Schleife, A. Janotti, C.G. Van De Walle, J.B. Varley, A. Schleife, A. Janotti and C.G. Van De Walle: 103 (2013) 82118.

36) H. Wang, K. Dou, W.Y. Teoh, Y. Zhan, T.F. Hung, F. Zhang, J. Xu, R. Zhang and A.L. Rogach: Adv. Funct. Mater. 23 (2013) 4847-4853.

37) D.S. Smith, A. Alzina, J. Bourret, B. Nait-Ali, F. Pennec, N. TessierDoyen, K. Otsu, H. Matsubara, P. Elser and U.T. Gonzenbach: J. Mater. Res. 28 (2013) 2260-2272.

38) A. Biancheria: Trans. Am. Nucl. Soc. 9 (1966) 15.

39) W. Zhou and N. Umezawa: Phys. Chem. Chem. Phys. 17 (2015) 17816-17820.

40) K. Inoue, S. Mori and A. Yamaguchi: J. Ceram. Soc. Jpn. 111 (2003) 348-351.

41) N. Soga and E. Schreiber: J. Am. Ceram. Soc. 51 (1968) 465-467.

42) D.H. Chung: Phys. Earth Planet. Inter. 8 (1974) 113-120.

43) P. Turkes, C. Pluntke and R. Helbig: J. Phys. C 13 (1980) 4941-4951.

44) O.L. Anderson: J. Phys. Chem. Solids 24 (1963) 909-917.

45) F. Birch: J. Geophys. Res. 66 (1961) 2199-2224.

46) S. Ganesan: Philos. Mag. 7 (1962) 197-205.

47) G.A. Slack: Solid State Phys. Acad. Press. 34 (1979) 1-71.

48) E.S. Toberer, A. Zevalkink and G.J. Snyder: J. Mater. Chem. 21 (2011) 15843-15852.

49) S.A. Miller, P. Gorai, U. Aydemir, T.O. Mason, V. Stevanović, E.S. Toberer and G.J. Snyder: J. Mater. Chem. C 5 (2017) 8854-8861. 